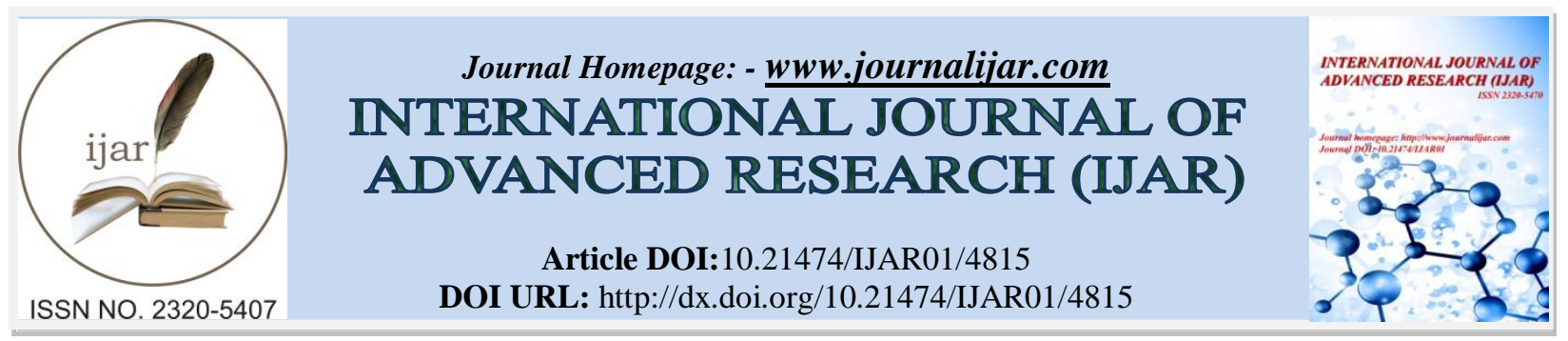

RESEARCH ARTICLE

\title{
DEVELOPMENT OF A NEW ADSORBENT MATERIAL BASED ON MARINE SPONGES OF THE GENUS IRCINA: APPLICATION OF THE EXPERIMENTAL DESIGN METHODOLOGY "SCREENING AND OPTIMIZATION".
}

\author{
${ }^{*}$ Zineb Rhandour ${ }^{1}$, Meriem Tarbaoui ${ }^{1}$, Mina Oumam ${ }^{2}$, Belkassem El Amraoui ${ }^{3,4}$ Ahmed Bennamara ${ }^{1}$ and \\ Abdelmjid Abourriche'. \\ 1. Biomolecular And Organic Synthesis Laboratory, Faculty Of Sciences Ben M'sikUniversity Hassan II- \\ Casablanca, Casablanca, Morocco. \\ 2. Limat (Engineering Materials Laboratory), University Of Hassan II-Casablanca,Casablanca, Morocco. \\ 3. Faculty polydisciplinary of Taroudant, university ibnZohr, Agadir, Morocco. \\ 4. Control quality in bio-control industry \& bioactive molecules laboratory,faculty of sciences El jadida, Morocco.
}

\section{Manuscript Info}

Manuscript History

Received: 11 May 2017

Final Accepted: 13 June 2017

Published: July 2017

Key words:-

Marine sponge, Adsorbent material, screening, Experimental design,

Optimization

\section{Abstract}

In this work, activated carbon was prepared from the by-product of marine sponges. The objective of this study is summarized in the development of an adsorbent material with a very interesting adsorption capacity, hence the interest to control the parameters influencing the functioning of the development process by exploiting it The screening plan "Factoriel Complet". This technique minimizes the experiments and allows detecting the factors influencing the quality and the quantity which are: temperature, time and mass. Then the next step in this study was devoted to the optimization of the process of elaboration, using the response surface methodology "Composite centered plan". The optimal conditions with 55\% of methylene blue adsorption capacity are obtained with $180.9^{\circ} \mathrm{C}$ as activation temperature, $118.9 \mathrm{~min}$ as activation time and $7.33 \mathrm{~g}$ for the mass of the raw material.

Copy Right, IJAR, 2017,. All rights reserved.

\section{Introduction:-}

Liquid industrial effluents present a great danger to the aquatic environment which is the main site of industrial and urban waste. Industrial waste water is causing enormous damage to the environment and health (Oumam et al.,2003). These releases have different degrees of harmfulness and this pollution is all the more dangerous because it is not known. In order to combat this dissolved pollution, several studies have been oriented towards economically acceptable processes using several techniques (Souabi et al., 1993 and Altinbas et al., 1995). These techniques could be divided into three types of treatment, namely biological, dielectric and physico-chemical treatments (Wanassi et al., 2017). These include adsorption and ion exchange (Tzvetkova et al., 2016). The aim of this work is to develop adsorbent materials having an adsorption capacity from the extraction residues of the Ircinia marine sponge, adopting the experimental design methodology in first the screening plan in order to master the influence of factors on the process of elaboration, followed by an optimization of the process by adopting a composite plan centered. This study has guided us in translating the evolution of the performance of the materials developed according to the different operating factors influencing the process.

Corresponding Author:-Zineb Rhandour.

Address Biomolecular and Organic Synthesis Laboratory, Faculty of Sciences Ben M'sik University

Hassan II- Casablanca, Casablanca, Morocco. 


\section{Materials and Methods:-}

\section{Sample:-}

The marine sponges were collected in winter 2015 at the littoral Atlantic of El-Jadida (Morocco). All the sponges were identified by Dr. Maria-JesúsUriz, Research Professor at the Centro de Estudios Avanzados de Blanes (CEAB) and Consejo superior de investigacione scientíficas (CSIC) Spain. The collected materials were immediately frozen for one night prior to extraction (Rhandour et al., 2016).

\section{Preparation of Samples:-}

The extraction residues obtained from these sponges were chemically activated using (phosphoric/ sulfuric) acid $2 \mathrm{M}$. The samples were baked overnight at $120^{\circ} \mathrm{C}$. and heat-treated in air, in a muffle furnace, at different temperatures, the treatment time varied. The samples are then washed with distilled water in a Soxhlet for 72 hours, in order to extract the excess acid and the soluble material, and then dried in the oven at $120^{\circ} \mathrm{C}$. The products are ground (granulometry less than $100 \mu \mathrm{m}$ ) (Tarbaoui et al., 2014).

\section{Experimental design Methodology:-}

\section{Screening plan:-}

The first problems which experimental design can give the solution are these of screening parameters "Complete factorial plans “. This study permitted to determine easily, among a large number of factors (k), those are significantly influenced to improve extraction process. This study will allow determining the "effect" of each level and for every factor, in objective to classify them in ascending order (Fadil et al., 2014). The table (tab.1) presents the factors studied with real and coded level.

Table 1:- Factors and their coded levels.

\begin{tabular}{|c|c|c|}
\hline Factors & Levels & Coded Levels \\
\hline Temperature $\left({ }^{\circ} \mathrm{C}\right)$ & 180 & -1 \\
\hline \multirow{2}{*}{ Time $(\mathrm{mn})$} & 350 & +1 \\
\hline \multirow{2}{*}{ Mass $(\mathrm{g})$} & 90 & -1 \\
\cline { 2 - 3 } & 180 & +1 \\
\hline Type of acid & 5 & -1 \\
\cline { 2 - 3 } & 10 & +1 \\
\hline Pretreatment & sulfuric & -1 \\
\hline & phosphoric & +1 \\
\hline & yes & -1 \\
\hline & no & +1 \\
\hline
\end{tabular}

Optimization plan:-

Response surface methodology (RSM) is a statistical method that uses quantitative data from appropriate experiments to determine regression model equations and operating conditions (Alam et al., 2007). RSM is a collection of mathematical and statistical techniques for modeling and analysis of problems in which a response of interest is influenced by several variables (Chaudhary et al., 2014). A standard RSM design called central composite design (CCD) (Tarbaoui et al., 2015). Which allow solving the optimization problems by determining the optimal levels of the factors giving rise to a desired response. They constitute a second stage of the study after screening plans designed to identify the most influential factors (Oumam et al., 2003). In order to optimize the production conditions of our adsorbent material, the composite centered plane was used in order to reduce the number of experimental tests necessary for the evaluation of the parameters determined by the screening plan (activation temperature, time, and the treated mass of the material) and their effects on the adsorption capacity of methylene blue (Marouane et al., 2012).

\section{Statistical Analysis:-}

The treatment of the results for the experimental models was carried out using experimental design software JMP. The adsorption capacity was compared with the ANOVA test, the Fisher Snedecor test and the student test. All statistical analyzes were carried out in $\mathrm{P}$ values $(\mathrm{P}<0.05)$. 


\section{Results and Discussion:-}

Screening plan:-

The "Complete factorial plan" is a pre-established plan in the JMP software. The experiment matrix is a table L8 (Tab. 2) which allows establishing the experimental plan.

Table 2:-Experiment matrix of the material produced from the sponge.

\begin{tabular}{|c|c|c|c|c|c|c|}
\hline $\mathrm{N}^{\circ}$ Test & $\begin{array}{c}\text { Temperature } \\
\left({ }^{\circ} \mathrm{C}\right) \mathrm{X}_{1}\end{array}$ & $\begin{array}{l}\text { Time } \\
(\mathrm{mn}) \mathrm{X}_{2}\end{array}$ & $\begin{array}{c}\text { Mass } \\
(\mathrm{g}) \mathrm{X}_{3}\end{array}$ & $\begin{array}{c}\text { Acid } \\
\mathrm{X}_{4}\end{array}$ & $\begin{array}{c}\text { Pretreatment } \\
\mathrm{X}_{5}\end{array}$ & $\begin{array}{c}\text { Adsorption } \\
\text { capacity } \%\end{array}$ \\
\hline 1 & 350 & 90 & 5 & phosphoric & no & 75.8 \\
\hline 2 & 350 & 180 & 10 & phosphoric & no & 55.3 \\
\hline 3 & 180 & 90 & 5 & sulfuric & no & 55.196 \\
\hline 4 & 180 & 180 & 10 & sulfuric & no & 21.41 \\
\hline 5 & 180 & 180 & 5 & phosphoric & yes & 13.4 \\
\hline 6 & 180 & 90 & 10 & phosphoric & yes & 9.13 \\
\hline 7 & 350 & 180 & 5 & sulfuric & yes & 13.17 \\
\hline 8 & 350 & 90 & 10 & sulfuric & yes & 7.3 \\
\hline
\end{tabular}

Validation of the Model:-

The quality of the adjusted model was expressed by the coefficient of determination $\mathrm{R}^{2}$, and its statistical significance was verified by an $\mathrm{F}$ test (analysis of variance) at the significance level of 5\%.

The linear regression of the Model:-

$\mathrm{R}^{2}$ measures the proportion of the total change in the mean response explained by the regression, it is the correlation between the observed and predicted response (Franco ., 2008). The goodness of the model is judged if the linear of regression coefficient is equal to or higher than 0.80 (Rhanzi. $\mathbf{N}$ et al., 2015). The linear analysis of regression as established by the experimental design JMP software are shown in the Figure 1. The calculated values of the coefficients of determination of the multilinear regression $\mathrm{R}^{2}$ equal to 0.99 is close to 1 and adjusted $\mathrm{R}_{\mathrm{A}}^{2}$ which is 0.97 (Tab.3) make it possible to confirm the validity of the model.

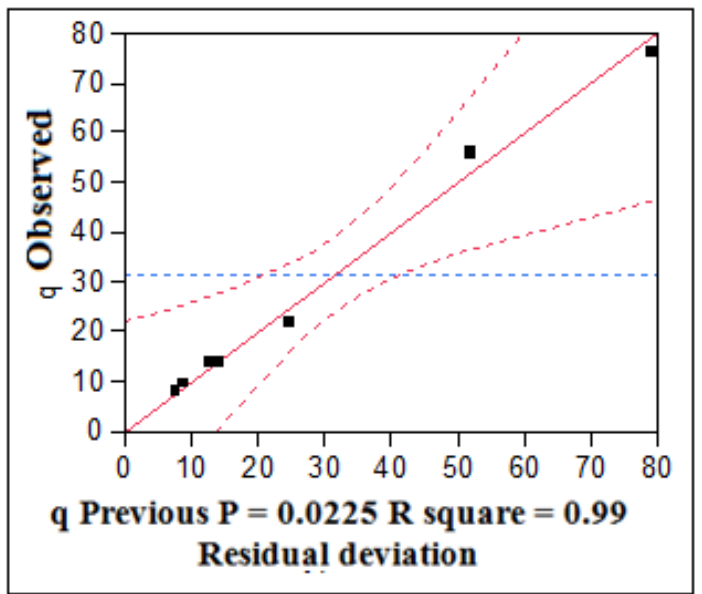

Figure 1:- Linear regression of Adsorption capacity.

Table 3:- Adjusted regression analysis of adsorption capacity.

\begin{tabular}{|c|c|}
\hline R square & 0.99 \\
\hline Adjested R square & 0.97 \\
\hline Root of square error of average & 4.73 \\
\hline Average of the reponse & 31.33 \\
\hline Observations (or weighted sums) & 8 \\
\hline
\end{tabular}




\section{Variance analysis:-}

The variance analysis is based on the comparison of the variance of the established model with the variance of the residue, using the Fisher Snedecor test. For the model to be very significant at $95 \%$, it is necessary that: Fexp $>>F \alpha$, $v_{\text {mod }}, v_{\text {res }}$ where $\alpha=0.05$. The results of the ANOVA given by the JMP software are shown in Table 4 . The results of analysis of the variance between the established model and the residue give an experimental factor Fexp (variance of the model / variance of the residue) $=43.75$.

From the results, we have Fexp $=43,75>>$ Fthéo, the condition of the Fisher Snedecor test is verified, so the regression is significant with a confidence threshold of $5 \%$.

The probability Prob> F is the P-value associated with $\mathrm{F}$ value given by the statistical software JMP. It was compared to the risk $\alpha=0.05$, then the P-value is strictly less than $\alpha=0.05$, this model is significant.

Table 4:- ANOVA test.

\begin{tabular}{|c|c|c|c|c|}
\hline Source & Degrees of freedom & Sum of squares & Average square & F value \\
\hline Modele & 5 & 1224.22 & 244.84 & 43.75 \\
\hline Residue & 2 & 11.19 & 5.59 & Prob. $>$ F \\
\hline Total & 7 & 1235.42 & & 0.0225 \\
\hline
\end{tabular}

Study of selected factors:-

Factors Statistically not negligible:-

Table 5 shows an increase in the adsorption capacity of methylene blue with the low temperatures, while with the increase in processing time and mass a decrease in adsorption capacity is observed. The t-test for the temperature, processing time, and mass coefficients showed that these factors influence process operation because their risks are significant $(<0.05)$.

\section{Factors Statistically negligible:-}

The pretreatment and the type of acid are the factors which do not affect the process of production of adsorbent, and therefore will be removed from the study. The screening plan helps to demonstrate the parameters which have little influence on the adsorption capacity and therefore choose those which appear to be more influential. These will be studied more precisely in the next section to allow better control of the process.

Table 5:- Significant effects.

\begin{tabular}{|c|c|c|c|c|r|}
\hline Terme & Estimation & $\begin{array}{c}\text { Standard } \\
\text { deviation }\end{array}$ & T value & T value & Prob.>|t| \\
\hline Temprature & -10.29 & 0,83 & -12.31 & \\
\hline Time & -4.026 & 0.83 & -4.81 & & 0.0065 \\
\hline Mass & -3.53 & 0.83 & -4.23 & \\
\hline Acid & 3.27 & 0,83 & 3.92 & & 0.04 \\
\hline Pretraitement (yes) & -2.75 & 0.83 & -3.30 & & 0.0594 \\
\hline
\end{tabular}

Optimization of the conditions for the preparation of adsorbent materials by the experimental design method "Composite centered plan":-

The results obtained in the previous part of this study allowed to choose the most influential variables on the adsorption capacity of the prepared material namely temperature, treatment time and mass. The next step of this study will be devoted to the optimization of the process of elaboration. The easiest way is to choose a plan of experiments with faces centered whose matrix and the experimental values of adsorption capacity are represented in Table 6.The exploitation of the results obtained for the response was carried out with the same approach. The evaluation of the overall quality of the postulated model makes it possible to know whether it adequately summarizes the results of the tests of the experimental design. The evaluation of the overall quality of the postulated model allows knowing if it adequately summarizes the results of the tests of the experimental design. 
Table 6:- Factors studied and field of study.

\begin{tabular}{|l|l|l|}
\hline & \multicolumn{2}{|c|}{ Limit of Domain } \\
\hline Factor & Minimum value & Maximum value \\
\hline Temperature $\mathrm{X}_{1}$ & 180 & 400 \\
\hline Treatment time $\mathrm{X}_{2}$ & 90 & 180 \\
\hline Mass $\mathrm{X}_{3}$ & 5 & 10 \\
\hline
\end{tabular}

The equation of quadratic model is expressed by a mathematical equation of $2^{\text {nd }}$ degree written in the following polynomial form:

$Y_{i}=b_{0}+\Sigma b_{i} X_{i}+\Sigma b_{i i} X_{i}^{2}+\Sigma b_{i j} X_{i} X_{j}+£_{i}$

$\mathrm{b}_{0}$ is the constant of the model. bi is the effect of factor $\mathrm{Xi}$. bij is the effect of the interactions between factors $\mathrm{i}$ and $\mathrm{j}$. bii is the quadratic effect and $£ \mathrm{i}$ is the residue.

\section{Matrix of experiments and realization of tests:-}

The realization of tests consists of measuring the responses for all combinations of the factors indicated in the test matrix and requires certain precautions both statistical order as practical. This is firstly the randomization of the order of the tests which consists in randomly sorting the order of the tests in order to eliminate the influence of the unknown process disturbing factors which may possibly be correlated with the order of the tests. If the order of the trials is not randomized the interfering factors correlated with certain factors of the plan can only be demonstrated by confirmatory tests carried out at the end of the analysis of the results. The optimum configuration obtained by modeling may not be reproduced due to external disturbances. The influence attributed to the factors of the plan can be distorted and the difficulty will then be to detect which factor is affected and by what disturbance. Similarly, during the tests, test sheets were prepared to report the process and to mark the observations and incidents that occurred during the experiments. This will help the experimenter to make a better analysis and an explanation of the obtained results. The response studied is the adsorption capacity. The test matrix is given in Table 7.

Table 7:- Experimental design in coded and reels variables for centered composite design, and test results

\begin{tabular}{|c|c|c|c|c|c|}
\hline Test number & Configuration & Temperature & Time & Mass & Adsorption capacity \% \\
\hline 1 & $00-\alpha$ & 290 & 135 & 5 & 11.5 \\
\hline 2 & --- & 224 & 108 & 6 & 25.6 \\
\hline 3 & +-- & 355 & 108 & 6 & 12.5 \\
\hline 4 & -+- & 224 & 162 & 6. & 67.6 \\
\hline 5 & ++- & 355 & 162 & 6.012 & 9.7 \\
\hline 6 & $0-\alpha 0$ & 290 & 90 & 7.5 & 54.3 \\
\hline 7 & $-\alpha 00$ & 180 & 135 & 7.5 & 7.3 \\
\hline 8 & 000 & 290 & 135 & 7.5 & 12.9 \\
\hline 9 & 000 & 290 & 135 & 7.5 & 12.6 \\
\hline 10 & 000 & 290 & 135 & 7.5 & 11.9 \\
\hline 11 & 000 & 290 & 135 & 7.5 & 11.8 \\
\hline 12 & $+\alpha 00$ & 400 & 135 & 7.5 & 13.3 \\
\hline 13 & $0+\alpha 0$ & 290 & 180 & 7.5 & 26.7 \\
\hline 14 & --+ & 224 & 108 & 9 & 10 \\
\hline 15 & +-+ & 355 & 108 & 9 & 40 \\
\hline 16 & -++ & 224 & 162 & 9 & 2.8 \\
\hline 17 & +++ & 355 & 162 & 9 & 12.9 \\
\hline
\end{tabular}

\section{Analysis of test Results:-}

\section{The linear regression of the model:-}

The essential characteristics of the fit of the quadratic model are given in Table 8 . The regression is illustrated by the graph of the responses measured as a function of the estimated responses which show the distribution of points around the regression line Fig. 2. The coefficient of determination $\mathrm{R}^{2}=0.98$ is close to 1 . This coefficient reflects the contribution of the model in the restitution of the variation of the observed response. It expresses the ratio between the variation due to the regression and the total variation. In the presence of several explanatory variables, we use 
the adjusted coefficient of determination (adjusted $R^{2}$ ) (adjusted $R^{2}$ is equal to $96 \%$ ). which reflects a good fit of the model and that the descriptive quality of the postulated model is satisfactory.

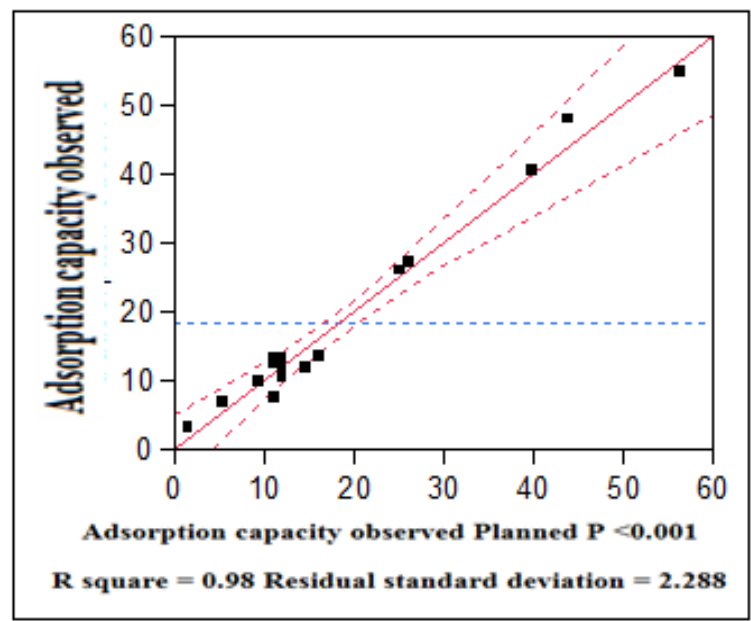

Figure 2:- Linear regression

Table 8:- Adjusted regression analysis of adsorption.

\begin{tabular}{|c|c|}
\hline R square & 0.98 \\
\hline R square adjusted & 0.96 \\
\hline Residual standard deviation & 2.88 \\
\hline Average response & 18.32 \\
\hline Observations (or weighted sums) & 18 \\
\hline
\end{tabular}

\section{Analysis of variance and lack of Adjustment:-}

According to Table 9. The Fisher Snedecor Fobs value is very high. Moreover.the probability that the variance of the model is significantly equal to the residual variance is less than the risk $\alpha=0.05$. This proves that the postulated model is consistent since the variance of the model is distinctly different from that of the residue. The lack of adjustment measures the difference between the a priori model (postulated model) chosen by the experimenter and the real model that governs the phenomenon studied. The sum of the squares of the lack of adjustment is equal to the difference between the sum of the squares of the residuals and the sum of the squares of the pure error.

Table 9:- Analysis of variance.

\begin{tabular}{|c|c|c|c|c|}
\hline Source & Degree (s) of freedom & Sum of squares & Average square & Report F \\
\hline Model & 9 & 3607.36 & 400.818 & 48.24 \\
\hline Residues & 8 & 66.46 & 8.308 & Prob. $>\mathrm{F}$ \\
\hline Total & 17 & 3673.83 & & $<.0001$ \\
\hline
\end{tabular}

The results presented in Table 10 show that the probability that the variance of the postulated model is significantly equal to the variance of the real model is lower than the 5\% risk. This allows us to deduce that the lack of fit is not due to the quadratic model.

Table 10:- Lack of adjustment.

\begin{tabular}{|c|c|c|c|c|}
\hline Source & Degree (s) of freedom & Sum of squares & Average square & Report F \\
\hline Lack of adjustment & 5 & 45.919676 & 9.18394 & 1.3409 \\
\hline Pure error & 3 & 20.547500 & 6.84917 & Prob. > F \\
\hline Total error & 8 & 66.467176 & & 0.4306 \\
\hline & & & & R carré max. \\
\hline
\end{tabular}




\section{Estimation of model Coefficients:-}

The analysis of the variance makes it possible to determine the factors and the most influential interactions on the performance of the coal elaborated in order to have an attractive adsorption capacity. The statistical analysis of the coefficients constituting the equation of the quadratic model is based on the null hypothesis $\mathrm{H}_{0}$ which states that the coefficient is zero. The diagrams shown in Table 11 make it possible to visually identify the factors most influential on the response. To achieve the objective of this study, which is summarized in the determination of the input factors that maximize the adsorption capacity, we validated the quadratic model.

Table 11:- Significant effects coefficients of established equation model.

\begin{tabular}{|c|c|c|c|c|c|}
\hline Terme & Estimation & $\begin{array}{l}\text { Standard } \\
\text { Deviation }\end{array}$ & Report t & Report t & Prob.>|t| \\
\hline Constant & 11.075145 & 1.439098 & 7.70 & & $<.0001$ \\
\hline Temperature & -13.15648 & 0.77998 & -16.87 & $\frac{1}{15}$ & $<.0001$ \\
\hline Temperature*Temperature & 8.1808174 & 0.810453 & 10.09 & $1=$ & $<.0001$ \\
\hline Temperature* Time & -6.075 & 1.019093 & -5.96 & \begin{tabular}{l|l} 
\\
\end{tabular} & 0.0003 \\
\hline Time & 2.0542398 & 0.77998 & 2.63 & 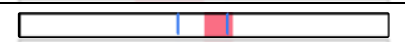 & 0.0300 \\
\hline Time*Mass & -1.225 & 1.019093 & -1.20 & 110 & 0.2637 \\
\hline Mass*Mass & 0.8092292 & 0.810453 & 1.00 & $\overline{111}$ & 0.3473 \\
\hline Mass & -0.750209 & 0.77998 & -0.96 & 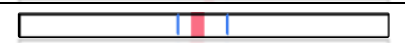 & 0.3643 \\
\hline Time*Time & 0.5617419 & 0.810453 & 0.69 & 111 & 0.5079 \\
\hline Temperature*Mass & 0.05 & 1.019093 & 0.05 & 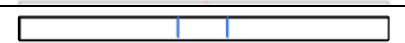 & 0.9621 \\
\hline
\end{tabular}

According to this graphic representation, the effects of temperature and time factors are significant, as is the effect of the interaction between temperature and time, and even the quadratic effect of temperature.

Therefore the estimated model relating to the adsorption capacity is written as indicated by the following formula:

\section{$Y=11,075-13,156 * X_{1}+2,054 * X_{2}-6,075 * X_{1} * X_{2}+8,180 * X_{1} X_{1}$}

The equation of the established model shows that the temperature has a negative effect, which means that the increase of this factor gives a decrease in the adsorption capacity. While the effect of treatment time is positive, indicating that our response increases with increasing contact time.

\section{Optimization and Desirability:-}

The overall desirability reflects a particular adjustment of the input factors which allow obtaining, from the empirical models, the values of responses within the tolerance intervals. This search is done iteratively in dedicated software. The modeled responses were transformed into desirability functions ranging from 0 to $100 \%$. This desirability reflects the degree of satisfaction of the experimenter as a function of the obtained value of the modeled response, after assigning it a target value to be achieved. A satisfaction index equal to $100 \%$ is assigned when the objective is reached, this index is equal to zero if the value of the modeled response is outside the tolerance interval associated with it. As soon as the level of a response does not belong to the tolerance interval associated with it, the value of the desirability function is zero.

The figure 3 shows the desirability functions of the adsorption capacity. It illustrates a case study where we set the target at $48.6 \%$, with a temperature equal to $180.9^{\circ} \mathrm{C}$. We then varied the other parameters in the field of study using the predictive profiler which allowed the values of the other input factors to be obtained with a processing time equal to $118.9 \mathrm{~min}$ and a mass equal to $7.33 \mathrm{~g}$. 


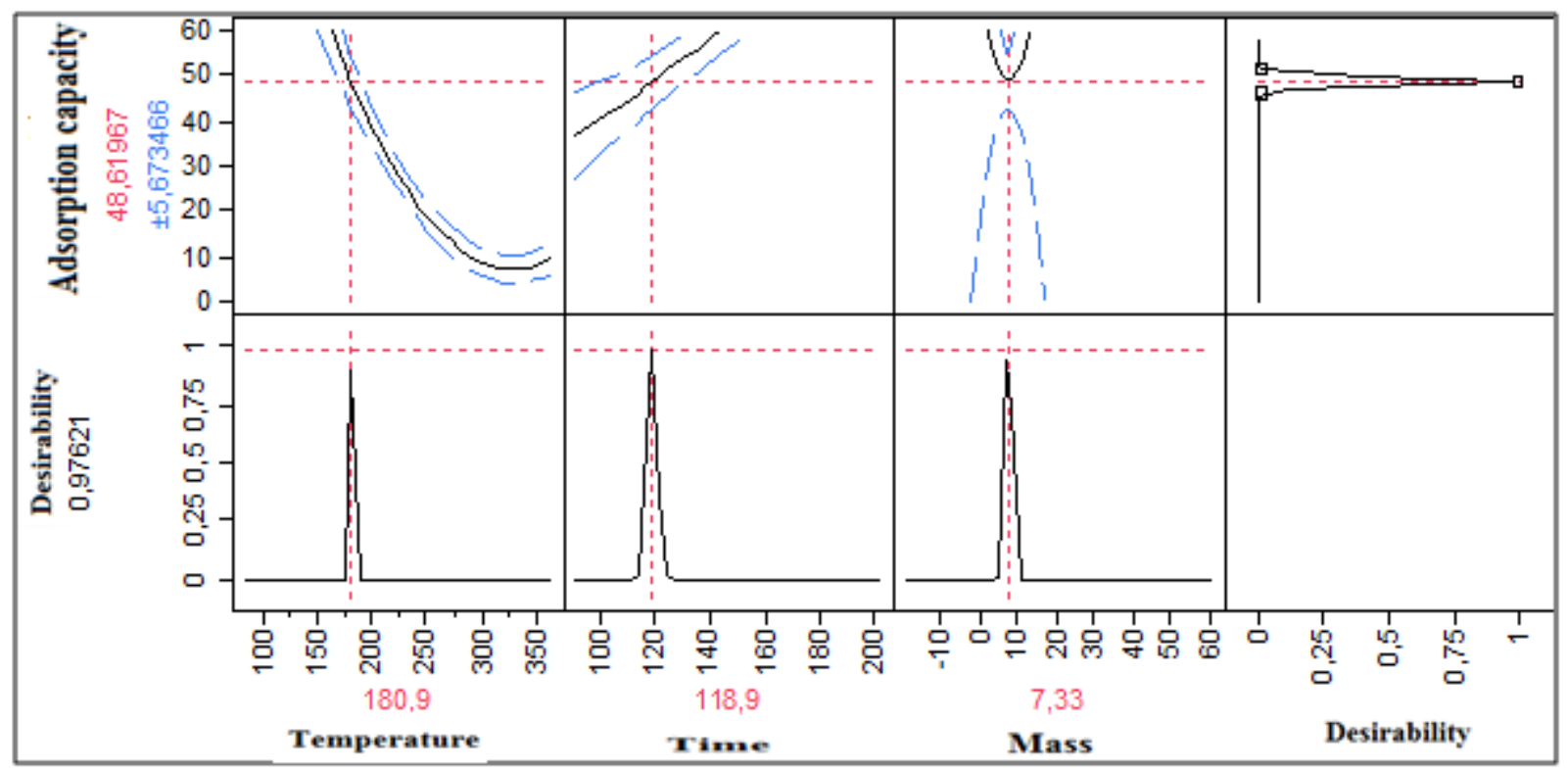

Figure 3:- Prediction profiler.

\section{Conclusion:-}

In this work, the effect of each factor involved in the process of preparation of the adsorbent materials was determined with the methodology of the experimental plans using a "Factoriel Complete" screening plan to have an adsorption capacity interesting. This method allowed us to select the factors influencing the performance of adsorbent elaborated which are the temperature, the time, and the mass of the raw material. Then, the central composite plan, established for the study of the quality of the adsorbent produced, was used to determine the optimum conditions for the development of adsorbent.

The results of the optimization of the operating conditions allowed us to obtain a material which has an adsorption capacity equal to $55 \%$. The three parameters were set at $\mathrm{T}=180.9^{\circ} \mathrm{C}, \mathrm{m}=7.33 \mathrm{~g}$, for $118.9 \mathrm{~min}$.

\section{References:-}

1. Oumam. M., Abourriche A., Adil.A.,Hannache.H., R.Lailler., Birot.R., PilloT.J.P.(2003): Elaboration and characterization of a new adsorbent material from Moroccan oil. Ann. Chim. Sci. Mat. (28) 59-74

2. Tzvetkova. P.G., Nickolov. R N., Tzvetkova C .Tz ,. Bozhkov. O. D., Voykova D. K. (2016): Diatomite/Carbon Adsorbent For Phenol Removal. J.Ch. T. and Met. (2). 202-209

3. Souabi.S ., Belkbir.M. (1993): Elimination of surfactants in water treatment by adsorption onto activated carbon. J. Soc. Mar. Chim. (2) 53-65

4. Wanassi1. B ., I Ben Hariz.I ., Ghimbeu.C .M., Vaulot. C., Mohamed Ben Hassen. M., Jeguirim.M.(2017): Carbonaceous adsorbents derived from textile cotton waste for the removal of Alizarin S dye from aqueous effluent: kinetic and equilibrium studies. Environ SciPollut Res. (11). 10041-10055

5. Altinbas.T ., Dokmeci. S., Baristiran.A. (1995): Treatability study of waste water from textile industry. Envir.Techn. (16) 389-394.

6. Tarbaoui. M., Oumam .M., El Amraoui.B., Fourmentin. S., Benzina.M ., Charrouf. M., Bennamara. A., Abourriche. A. (2014): Elaboration, caractérisationetévaluation des performances d'un nouveau matériauadsorbant à base des éponges marines: application dansl'adsorption des composésorganiquesvolatils (Elaboration, characterization and evaluation of the performance of a new adsorbent material based of marine sponges: application in adsorption of volatile organic compounds).J. Mater. Environ. Sci. (5) 2163-2168.

7. Fadil .M.,Abdellah. F., IHSSANE. B., Rachiq.S. (2014): The application of Plackett and Burman design in screening the parameters acting on the hydrodistillation process of Moroccan thyme. IJIAS (6) 530-540

8. Alam. M.Z., Muyibi .S.A., J. Toramae. (2007): Statistical optimization of adsorption processes for removal of 2,4-dichlorophenol by activated carbon derived from oil palm empty fruit unches. J. Env.Sc.s, 19(6). 674-677. 
9. Chaudhary .N., Balomajumder .C. (2014): Optimization study of adsorption parameters for removal of phenol on aluminum impregnated fly ash using response surface methodology, Journal of the Taiwan Institute of Chemical Engineers, 45(3).852-859.

10. Tarbaoui. M., Oumam .M.,Fakhfakh .N., El Amraoui. B., Benzina .M ., Charrouf. M., Bennamara. A., Abourriche. A. ( 2015): Optimization of conditions for the preparation of new adsorbent material from residues of marine sponges using experimental design method. ACAIJ, 15(2). [054-064]

11. Marouane .S.,Oumam. N., Abourriche. A., Bennamara. A., Charrouf. M. (2012): Optimization of activated carbon from residues of oregano using experimental design method. Med. J.Chem. 1(5). 210-220

12. Franco.J. (2008): Planification d'expériences numériques en phase exploratoire pour la simulation des phénomènes complexes. Saint-Etienne. France.pp-12

13. Rhazi. N., Hannache .H., Oumam. M., Sesbou. A., Charrier. B., Pizzi. A., Charrier-El Bouhtoury. F.(2015): Green extraction process of tannins obtained from Moroccan Acacia mollissima barks by microwave: Modeling and optimization of the process using the response surface methodology RSM. arabjc.04.032. 1-7 